This PDF is a selection from a published volume from the National Bureau of Economic Research

Volume Title: Economic Aspects of Obesity

Volume Author/Editor: Michael Grossman and Naci H. Mocan, editors

Volume Publisher: University of Chicago Press

Volume ISBN: 0-226-31009-4

ISBN13: 978-0-226-31009-1

Volume URL: http://www.nber.org/books/gros09-1

Conference Date: November 10-11, 2008

Publication Date: April 2011

Chapter Title: The Impact of Minimum Wage Rates on Body Weight in the United States

Chapter Authors: David O. Meltzer, Zhuo Chen

Chapter URL: http://www.nber.org/chapters/c11815

Chapter pages in book: $(17$ - 34) 


\title{
The Impact of Minimum Wage Rates on Body Weight in the United States
}

\author{
David O. Meltzer and Zhuo Chen
}

Since 1970, the rate of obesity in the United States has increased from about 14 percent to over 25 percent and has come to be recognized as a major public health concern (NIH 1998; Flegal et al. 1998, 2005; Ogden et al. 2006). Understanding the causes of obesity is important because it may suggest strategies to address the increase in obesity. Increases in body weight are the result of an excess of caloric intake relative to caloric expenditure. Changes in both caloric expenditure and caloric intake have been hypothesized to have contributed to increasing obesity in the United States. Factors that have been suggested to have decreased caloric expenditure include the development of a more sedentary lifestyle due to the decreasing role of physical labor in work and the increasingly sedentary nature of leisure activities due to the growth of television and video games. Factors affecting food consumption that have been emphasized include the greater consumption of "fast-food" away from home and the declining cost of eating a diverse set of foods at home due to the increased availability of low-cost prepared and highly

David O. Meltzer is associate professor in the Department of Medicine and associated faculty member in the Harris School of Public Policy and the Department of Economics at the University of Chicago, and a research associate of the National Bureau of Economic Research. Zhuo Chen is an economist at The Centers for Disease Control and Prevention (CDC), U.S. Department of Health and Human Services.

The authors would like to acknowledge the financial support of the Chicago Center of Excellence in Health Promotion Economics (P30 CDC000147-01, PI: Meltzer) from the Centers for Disease Control and Prevention and a Midcareer Career Development Award from the National Institute of Aging (1 K24 AG031326-01, PI: Meltzer). Dr. Meltzer would also like to acknowledge salary support from the Agency for Healthcare Research and Quality through the Hospital Medicine and Economics Center for Education and Research on Therapeutics (CERT) (U18 HS016967-01, PI: Meltzer). The work of Zhuo Chen was done when he was a postdoctoral scholar at the Chicago Center of Excellence in Health Promotion Economics, The University of Chicago. 
processed foods (Cutler, Glaeser, and Shapiro 2003; Philipson and Posner 2003; Mello, Studdert, and Brenna 2006; Nestle 2006).

The consumption of fast-food has received particular attention as a cause of obesity. Chou, Grossman, and Saffer (2004) found that people who live in closer proximity to fast-food restaurants are more likely to be obese. However, this finding might not reflect a causal effect of the presence of fast-food restaurants on obesity, but instead a tendency for fast-food restaurants to locate in areas where the demand for their products will be greater. Even if this association were viewed to reflect a causal effect of fast-food restaurants on obesity, it would not explain why the number of fast-food restaurants should have increased. Recent studies present mixed evidence. Anderson and Matsa (2009) found no causal link between proximity to restaurants and obesity. Currie et al. (2009) used data from 3 million school children in California and over 1 million pregnant women in Michigan, New Jersey, and Texas to estimate the impact of fast-food restaurants on obesity. They found that a fast-food restaurant within a tenth of a mile of a school is associated with 5.2 percent increase in obesity rates among ninth grade children, and that a fast-food restaurant within a half mile of residence results in a 2.5 percent increase in the probability of gaining over 20 kilograms among pregnant women.

Because minimum wage labor makes up about one third of the cost of fast-food, and because the real minimum wage has varied nationally and across states over time due to inflation and changes in state and federal minimum wage laws that would not seem to have any independent reasons to affect obesity, variation in real minimum wages may provide a powerful mechanism to provide a test for the hypothesis that fast-food consumption may play a role in increasing obesity in the United States. While the variation in the real minimum wage across states over time is the critical element for this test of the hypothesis, the fact that the real minimum wage in 2007 constant dollars fell from a maximum of about $\$ 9.15$ in 1968 to a low of about $\$ 5.80$ in 2007 suggests that it is possible that the decline in real minimum wage itself may have played a role in the long-term increase in obesity over this period. ${ }^{1}$ Although our analysis does not support a direct test of the hypothesis that a decline in the minimum wage could affect obesity by increasing the consumption of fast-food, we complement this analysis in our discussion by calibrating our findings against the results of other studies that have examined how declines in the minimum wage would translated into lower prices for food away from home (Aaronson, French, and MacDonald 2008; Aaronson 2001; MacDonald and Aaronson 2006; Lee and O'Roark 1999; Piggott 2003) and how increased consumption of food away from

1. Nominal minimum wage rates can be found in a document provided by the Employment Standard Administration, U.S. Department of Labor, "Changes in basic minimum wages in non-farm employment under state law: Selected years 1968 to 2008." Available at: http://www .dol.gov/whd/state/stateMinWageHis.htm. 
home would increase obesity (Chou, Grossman, and Safer 2004). Since the results of this calibration exercise are similar in magnitude to the results of our primary analysis of the association of minimum wages and obesity, this helps provide confidence that the association we observe may reflect a causal pathway to obesity through increased consumption of fast-food. We also recognize that increases in the minimum wage may affect incomes. However, as we will discuss later, because a relatively small fraction of the population earns minimum wage and because the effects we find are larger in higher income persons, we do not think this potential income effect explains our findings.

\subsection{Methods}

Real minimum wages were calculated using data on nominal minimum wages and consumer price indices (CPI) from 1984 to 2006, the years for which our obesity data were available. Nominal minimum wage data by state was obtained from the Bureau of Labor Statistics. ${ }^{2}$ We then calculated the real wage rates in 2006 dollars by dividing the nominal wage rates by the census-region-specific all items CPI. ${ }^{3}$ Because most fast-food restaurants are part of chains that are classified as interstate commerce and are therefore subject to federal minimum wage legislation, ${ }^{4}$ we used the higher of the federal minimum wage and the state minimum wage. Figure 1.1 reports the trends in mean nominal and real minimum wage rates across states, weighted to reflect the distribution of population in our obesity data, which is intended to be representative of the U.S. noninstitutionalized adult population. The pattern of changes in these average real minimum wages reflects a combination of federal nominal minimum wages increases in 1990 and 1996 (denoted by large squares) and multiple state increases over time, and the tendency for inflation to erode the average real minimum wage in the absence of legislated increases. Despite the two increases in the federal minimum wage and numerous increases in state minimum wages, the mean real minimum wage rate faced by respondents in our sample declined from $\$ 6.40$ in 1984 to $\$ 5.82$ in 2006 . Although this overall change was modest, the powerful effect of the federal minimum wage caused much larger variations in average real minimum wages over shorter time periods. For example, from September 1997 when the federal minimum was raised to $\$ 5.15$ an hour to the end of the period studied, the average real minimum wage fell from $\$ 6.47$ to $\$ 5.82$. Seventeen states had state minimum wage rates above the federal minimum wage by April 2006. Oregon, Vermont, and Washington

2. Full set of the minimum wage rates data is compiled by using various issues of Monthly Labor Review. Available at: http://www.bls.gov/opub/mlr/archive.htm.

3. Bureau of Labor Statistics, U.S. Department of Labor (July series, without seasonal adjustment) extracted from the BLS website. Available at: http://www.bls.gov/CPI/\#data.

4. U.S. Department of Labor, Employment Standards Administration (2004). 

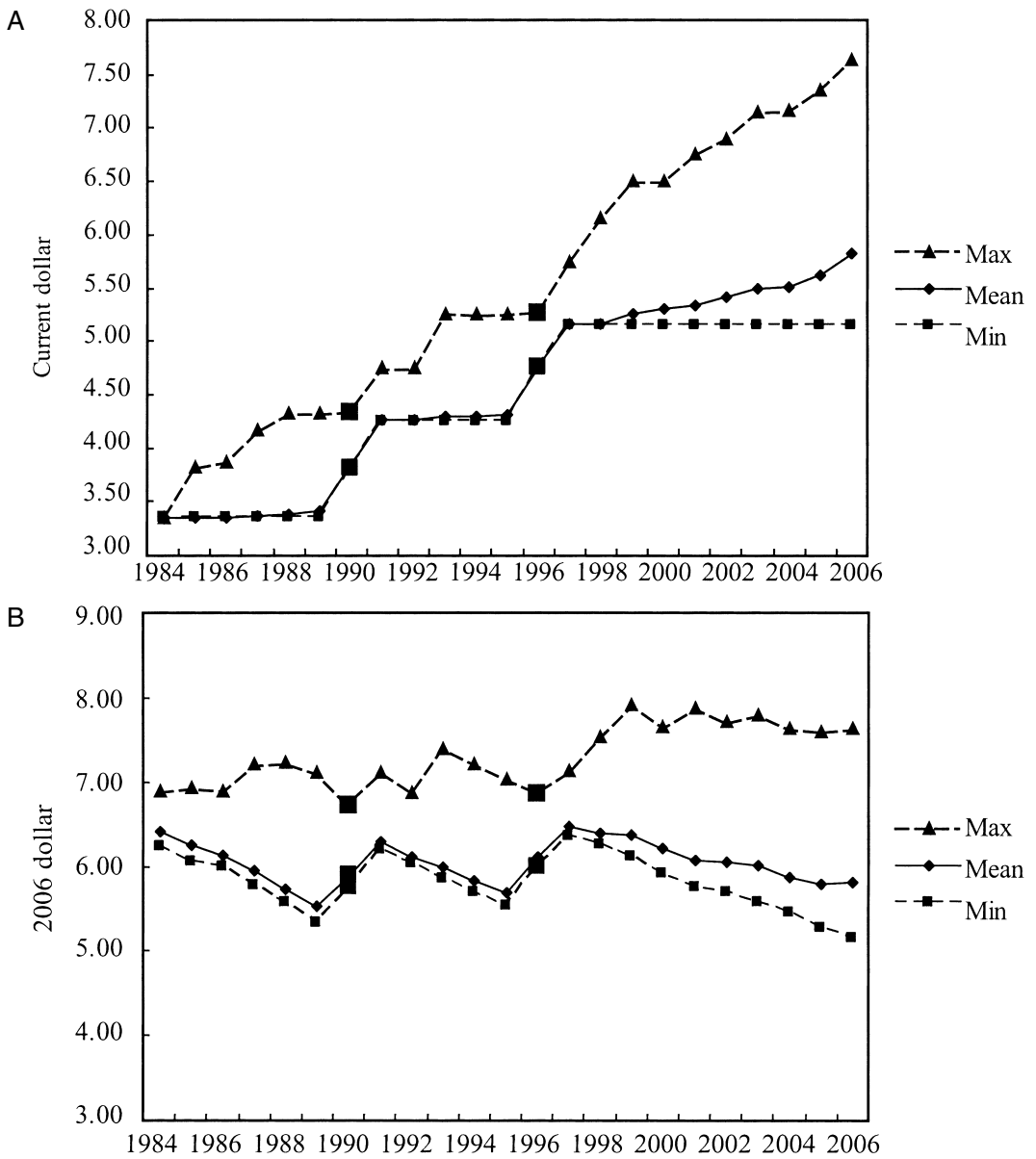

Fig. 1.1 Nominal (panel $\boldsymbol{A}$ ) and real (panel $\boldsymbol{B}$ ) minimum wage in the United States. Enlarged squares indicate values at 1990 and 1996, when increases in federal minimum wage occurred.

automatically adjust minimum wage rates each year using state consumer price indices.

We studied the effects of these minimum wage changes among respondents to the Behavior Risk Factor Surveillance System (BRFSS) from 1984 to $2006 .^{5}$ The BRFSS surveys health risk behaviors among noninstitutionalized American civilian adults age 18 and older and is the most commonly used source of data for national studies of obesity and physical activity in the United States (See Chou, Grossman, and Saffer 2004). Data for BRFSS 
is collected by state health departments using computer assisted telephone interviewing with coordination by the Centers for Disease Control and Prevention (CDC). When data collection for BRFSS began, only fifteen states participated. However, by 1994, all fifty states, the District of Columbia, and three territories participated.

The 1984 to 2006 BRFSS includes 3,256,947 valid interview records. We excluded pregnant women $(33,385)$ and records with missing information on weight, height, and key confounding factors $(165,410)$. We also excluded records with values of body mass index (BMI) (weight in kilograms divided by height in meters squared) that we considered implausible: 863 with BMI $<14$ and 8,911 with BMI $>50$. This left a final study sample of $3,048,378$ individuals with complete information. The CDC BRFSS group provides a final sampling weight to account for the sampling design. Figure 1.2

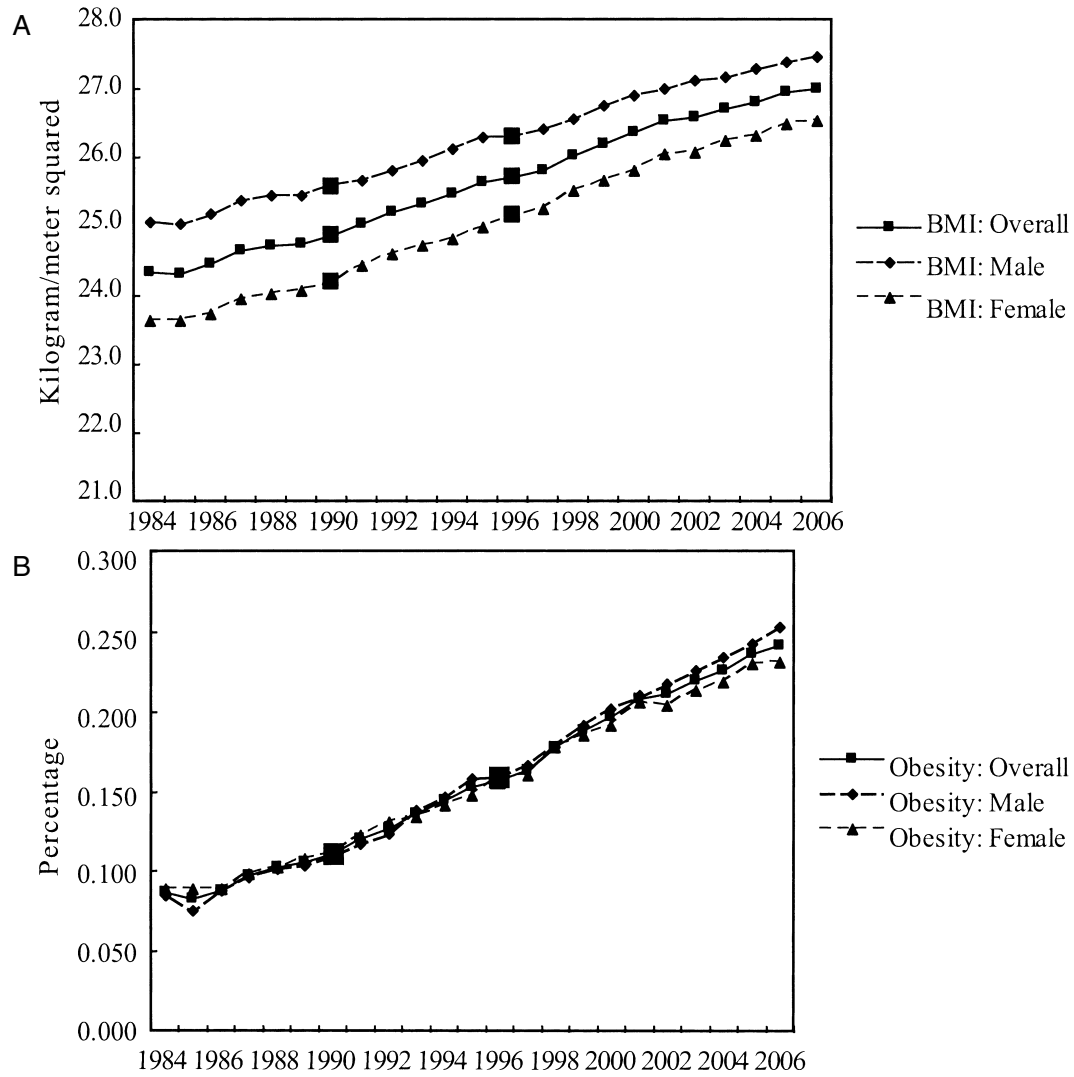

Fig. 1.2 Average BMI (panel $A$ ) and obesity prevalence (panel $B$ ) among the BRFSS sample. Enlarged squares indicate values at 1990 and 1996, when increases in federal minimum wage occurred. 
illustrates the trend of the weighted mean of BMI and proportion of obesity individual among the BRFSS sample and subsamples by gender group.

\subsection{Empirical Analysis}

Multivariate linear regression models were used to study the effects of the real minimum wage on BMI. Regressions controlled for race and ethnicity, age, marital status, education, income, state fixed effects, and year effects, with coding as described in table 1.1. Categories for household income interval indicators were obtained from the original surveys. Due to changes in

Table 1.1

Summary statistics of the BRFSS sample: 1984-2006

\begin{tabular}{|c|c|c|c|}
\hline Characteristics & $\begin{array}{c}\text { Overall } \\
(N=3,048,378)\end{array}$ & $\begin{array}{c}\text { Male } \\
(N=1,274,462)\end{array}$ & $\begin{array}{c}\text { Female } \\
(N=1,773,916)\end{array}$ \\
\hline Body mass index & $25.812 \pm 0.005$ & $26.401 \pm 0.007$ & $25.231 \pm 0.007$ \\
\hline Obese & 0.166 & 0.169 & 0.163 \\
\hline Minimum wage: CPI adjusted, 2006 dollar & $6.032 \pm 0.001$ & $6.033 \pm 0.001$ & $6.032 \pm 0.001$ \\
\hline Minimum wage: nominal & $4.714 \pm 0.001$ & $4.72 \pm 0.002$ & $4.708 \pm 0.001$ \\
\hline Age & $44.787 \pm 0.019$ & $43.432 \pm 0.028$ & $46.127 \pm 0.026$ \\
\hline White (reference) & 0.765 & 0.764 & 0.766 \\
\hline Black & 0.093 & 0.086 & 0.101 \\
\hline Hispanic & 0.097 & 0.102 & 0.093 \\
\hline Others & 0.044 & 0.048 & 0.040 \\
\hline Less than high school (reference) & 0.051 & 0.051 & 0.050 \\
\hline Some high school & 0.089 & 0.087 & 0.092 \\
\hline High school or GED & 0.323 & 0.310 & 0.336 \\
\hline Some college & 0.262 & 0.253 & 0.271 \\
\hline College or above & 0.275 & 0.300 & 0.251 \\
\hline Married (reference) & 0.090 & 0.077 & 0.101 \\
\hline Divorced & 0.090 & 0.077 & 0.101 \\
\hline Widowed & 0.071 & 0.027 & 0.115 \\
\hline Separated & 0.022 & 0.018 & 0.026 \\
\hline Never been married & 0.192 & 0.221 & 0.162 \\
\hline Member of an unmarried couple & 0.026 & 0.028 & 0.025 \\
\hline Income less than $\$ 10 \mathrm{k}$ (reference) & 0.079 & 0.061 & 0.098 \\
\hline Income btw $\$ 10 \mathrm{k}$ and $\$ 15 \mathrm{k}$ & 0.069 & 0.061 & 0.077 \\
\hline Income btw $\$ 15 \mathrm{k}$ and $\$ 20 \mathrm{k}$ & 0.081 & 0.076 & 0.085 \\
\hline Income btw $\$ 20 \mathrm{k}$ and $\$ 25 \mathrm{k}$ & 0.093 & 0.093 & 0.094 \\
\hline Income btw $\$ 25 \mathrm{k}$ and $\$ 35 \mathrm{k}$ & 0.142 & 0.148 & 0.137 \\
\hline Income greater than $\$ 35 \mathrm{k}$ & 0.413 & 0.458 & 0.369 \\
\hline Income missing & 0.122 & 0.104 & 0.141 \\
\hline Income greater than $\$ 50 \mathrm{k}$ & 0.148 & 0.165 & 0.131 \\
\hline Income greater than $\$ 75 \mathrm{k}$ & 0.107 & 0.123 & 0.092 \\
\hline Male & 0.497 & & \\
\hline
\end{tabular}

${ }^{a}$ All mean values are weighted. Cells with plus-minus signs indicate means \pm Taylor linearized standard errors. 
survey design over time, the indicator for household income greater than $\$ 50,000$ applies only to responses after 1984 , and the indicator for income greater than $\$ 75,000$ applies only from 1994 to 2006 . We assign zero to these variables when they are not applicable. Because the categorical nature of these income variables makes adjustment for inflation difficult, we include interaction terms of categorical income indicators and years. In addition, we also examined specifications that did not include income and that interacted income with indicators for time period. Furthermore, because the minimum wage could have a direct effect on income, especially for low income persons (Lakdawalla and Philipson 2002), we also examined specifications that divided the sample into high and low income groups that were further divided by educational attainment. Because health status and weight may decline with advancing age and more rapidly among older persons, we estimated models without persons older than sixty. Because trends in minimum wage and obesity may vary across states, we added interaction terms to control for state-specific linear trends. We estimated all models on the full sample and on male and female samples separately. Robust or Huber-White errors are used in calculating the confidence intervals and the $p$-values to account for serial correlation and state clustering in the linear models (Bertrand, Duflo, and Mullainathan 2004).

The effects of the minimum wage on body weight might not be uniform across different parts of the body weight distribution, thus we also examined our model using quantile regressions.

Statistical analyses were performed using the survey data analysis commands of Stata software, version 9 (Stata Corporation).

\subsection{Results}

The summary statistics are presented in table 1.1. Over the study period, the average BMI is 25.8 for the full sample, 26.4 for men, and 25.2 for women. The percentage of obese individuals is roughly 17 percent for the full sample and for both genders. The weighted mean age is 44.8 for full sample, but the male sample is about two years younger than the female sample. This presumably reflects the greater life expectancy of women.

Table 1.2 provides the estimates of the linear regression models for BMI. The results suggest that a one-dollar increase in minimum wage is associated with a 0.06 decrease in mean BMI. The results for male and female samples separately are similar.

Quantile regression results showed that the effects vary by BMI, with the effects increasing steadily across the BMI distribution to a maximum effect of a one dollar increase in the real minimum wage on BMI of 0.13 for the ninetieth percentile. Results were again similar when men and women were analyzed separately (see figure 1.3). 


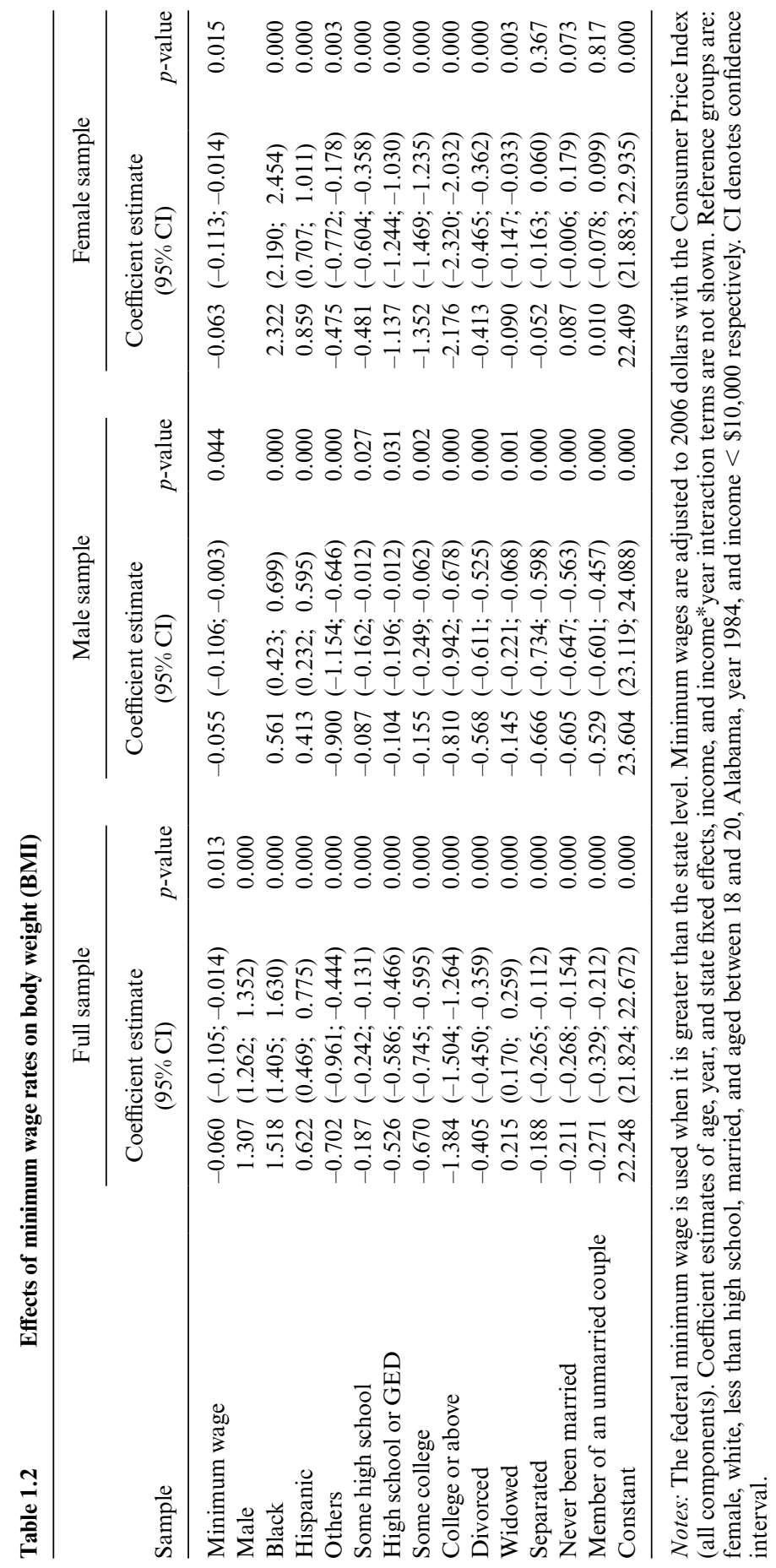




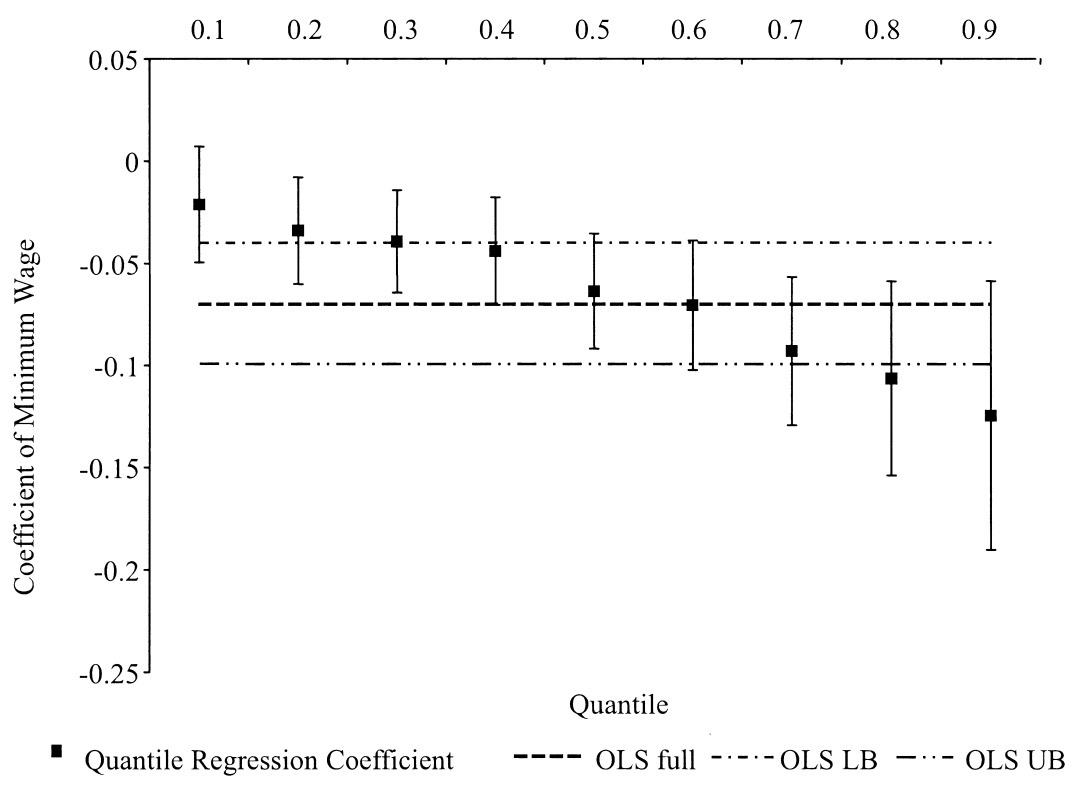

Fig. 1.3 Quantile regression effects of minimum wage on BMI

\subsection{Contribution of Minimum Wage Decreases to Increasing BMI and Obesity}

During the period covered by the BRFSS data, the average real minimum wage fell from a maximum of $\$ 6.40$ in 1984 to $\$ 5.82$ in 2006, with the federal minimum real wage falling even further, from $\$ 6.30$ to $\$ 5.20$. From when the federal minimum wage was last increased during our study period (1997) to the conclusion of our study period in 2006, the average real minimum wage fell from $\$ 6.50$ to $\$ 5.82$, and the real value of the federal minimum wage fell from $\$ 6.40$ to $\$ 5.20$. Multiplying these changes in the average real wage by the estimates from the linear model suggest that the $\$ 0.58$ decline in the real minimum wage from 1984 to 2006 would produce a $\$ 0.58 \cdot 0.06=0.035$ increase in BMI. Since average BMI increased by about 2.6 from 1984 to 2006 (from about 24.4 to 27.0 ), this is only 1 to 2 percent of the increase in BMI over the period. If we consider the most recent period during which the real minimum wage has been continuingly decreasing, 1997 to 2006, the $\$ 0.68$ decline can explain $0.68 \times 0.06=0.04$ (4 percent) of the 1.3 ( 25.7 to 27 ) increase in BMI. However, both these periods exclude the major decline in the real minimum wage that occurred from about 1970 to 1984 . If the longer term $\$ 3.33$ decline in the real minimum wage from its peak at $\$ 9.15$ in 1968 to $\$ 5.82$ in 2006 is considered, it can explain $3.33 \times 0.06=0.2$ (10 percent) of the total increase in average BMI from 25.0 to 27.0 over the period (Flegal et al. 1998; Kuczmarski et al. 1994). 
Table 1.3 presents results of the sensitivity analysis. The first two specifications show that the results are robust to whether they include the controls for income. Specifications 3 and 4 show the results are stronger for persons below age sixty than for older persons. Specifications 5 to 8 show that, excluding persons older than sixty among whom income is more likely to be a misleading measure of financial resources, the effects of minimum wage on BMI are greatest among persons with at least a high school education and with incomes above $\$ 35,000$. Specification 9 shows that our results are robust to the inclusion of state-specific linear trends. We include this specification test because we did not include state-specific time trends in an earlier version of this manuscript, and this was highlighted by discussants of our initial paper and by a later manuscript by Cotti and Tefft (2009) that did not find an effect of minimum wages on obesity. However, as specification 9 indicates, inclusion of this time trend did not change our results. Reasons we have considered for the difference between their findings and ours include that they (a) controlled for fast-food price, which creates potential problems of endogeneity and multicollinearity since fast-food price likely depends on minimum wage, (b) did not account for the BRFSS sampling weights, (c) used a much smaller number of observations than we used, without an apparent cause of the smaller sample size, and (d) used a correction for potential bias in self-reported BMI that was based on the relationship between self-reported and clinically measured body weight and height in the National Health and Nutritional Examination Survey (NHANES). We chose not to use this correction because we are concerned that it may not be appropriate for BRFSS because NHANES respondents knew that the measures they reported would be verified by a physical exam, but BRFSS respondents knew their reports would not be verified.

\subsection{Discussion}

The association we observe between changes in the real minimum wage and BMI among BRFSS respondents are consistent with our hypothesis that a decrease in real minimum wage rates can increase body weight. Although we cannot prove that this relationship is causal, several lines of evidence argue against alternative interpretations, such as that changes in body weight influence real minimum wage rates, or that a third factor influences both real minimum wage rates and body weight. The first possibility seems unlikely because there is no apparent reason why changes in obesity would cause changes in minimum wage laws or inflation. It does seem possible that some third factor could lead to both decreases in the real minimum wage and increases in BMI. One candidate might be that falling incomes within states that we somehow do not adequately control for could both cause states to allow the minimum wage to drift downward and lead to increases in obesity if declines in socioeconomic status due to falling incomes caused people to 


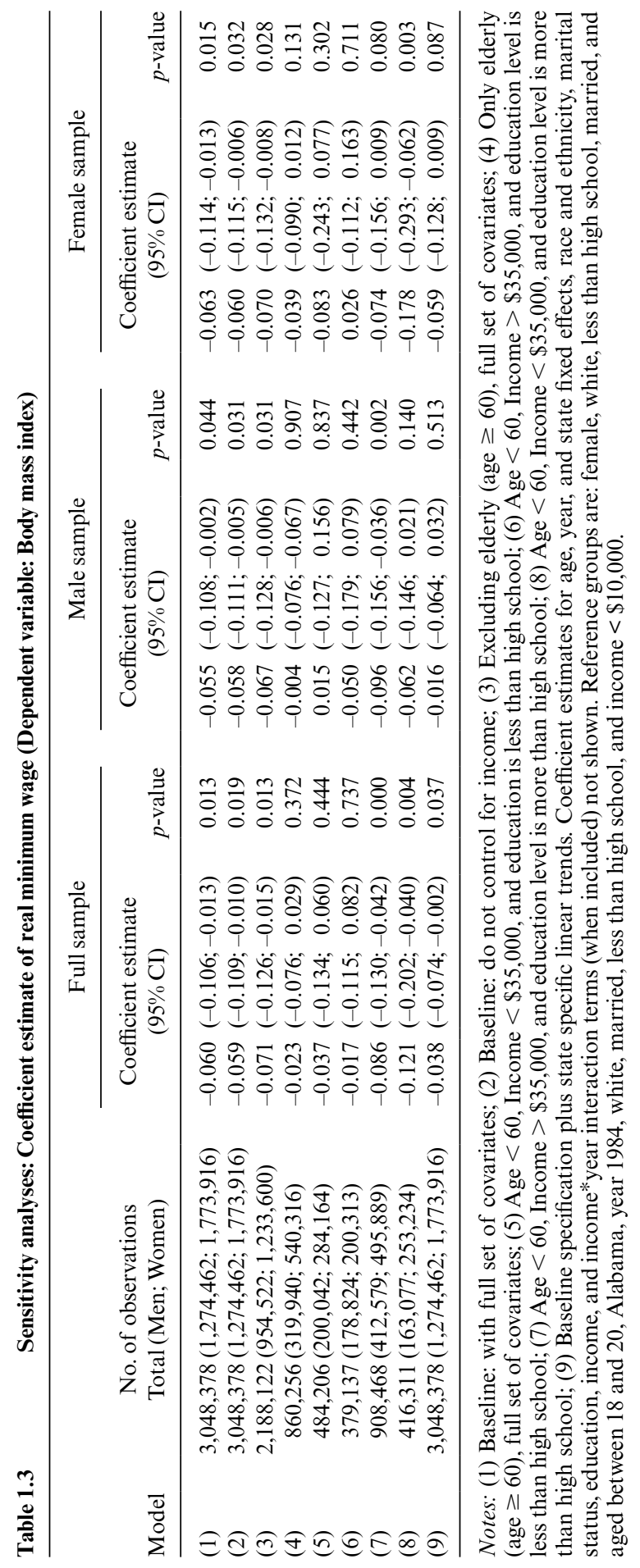


substitute cheaper but more fattening foods for more expensive ones that are less likely to cause obesity. Arguing against this is that we control for both state fixed effects and time trends, so that changes in state minimum wage legislation or local price levels would have to be explained by changes in income over time within states. We also performed additional sensitivity analyses that included state-specific time linear time trends, and these generally confirmed our overall findings, though these specifications have had difficulties converging in some of the quantile regressions.

The hypothesis that changes in the real minimum wage could cause changes in obesity, in contrast, seems highly plausible. Here, there are at least two stories one could tell. The first is the one that we have emphasized - that decreases in the minimum wage would lower the price of fastfood and thereby increase its consumption, and thus, obesity. The second is that a decrease in the minimum wage could raise obesity by lowering incomes of people who earn minimum wage and encouraging them to eat more unhealthy food. However, this second argument is not a convincing explanation of the results we observe because the effect of the minimum wage is greater among high income persons than among low income persons, who would be most likely to earn minimum wage. In addition, low income persons consume so little food away from home, $(<\$ 250$ per family of four per year), that it seems unlikely to be enough to contribute to obesity (Frazao et al. 2007). It is also interesting that even though lower income persons are more likely than higher income persons to be obese (Gibson 2003, 2004; Kim et al. 2006), obesity has increased most among higher income persons in recent years, as might be expected if changes in the price of food away from home were driving increases in obesity (Chang and Lauderdale 2005).

Further evidence supporting the hypothesis that the decline in real minimum wage has increased obesity by encouraging food away from home (FAFH) is that the effect we observe can be assessed by calibrating it against the published literature on how the price of food away from home affects the quantity of it consumed and how that, in turn, affects obesity. To do this, the effect of the minimum wage on BMI can be approximated by:

$\Delta \mathrm{BMI} / \Delta$ minimum wage $=\Delta \mathrm{BMI} / \% \Delta$ calories intake

. $\% \Delta$ calories intake $/ \% \Delta$ quantity of FAFH

.$\% \Delta$ quantity of $\mathrm{FAFH} / \% \Delta$ price FAFH

. $\% \Delta$ price $\mathrm{FAFH} / \% \Delta$ minimum wage

Assuming the median height of a person in the United States of 1.78 meters and average caloric intake of about 2000 calories per day, and estimates by Cutler, Glaeser, and Shapiro (2003) that the approximately $5 \mathrm{~kg}$ (equivalent to 1.6 unit of BMI) increase in median weight over the past two decades requires a net caloric imbalance of about 100 to 150 calories per day, the 
change in BMI per percent increase in caloric intake can be estimated as $\left(5 \div 1.78^{2}\right) \div(125 / 2000)=25$. Estimates of the elasticity of FAFH with respect to price are available from a recent study on demand of food consumption, which suggested estimates of price elasticity as from -2.03 to -1.16 (Lee and O'Roark 1999; Piggott 2003). Estimating how total calories consumed increases as FAFH increases is difficult because FAFH may substitute for food at home. However, assuming it does not subsitutue for food at home places an upper bound on the increase in total calories. Aaronson, French, and MacDonald (2008) have provided fairly consistent estimates of the effect of minimum wage on food price, ranging from elasticity estimates of 0.73 percent for full service establishments, to 1.56 percent for limited service establishments, for a 10 percent change of minimum wage. An alternative study suggested that 1 percent change of food price per $\$ 0.50$ change in minimum wage rate, consistent again with about a 1 percent change (Lee and O'Roark 1999). Multiplying these $(25 \times(-1.16$ to -2.03$) \times 0.01)=-0.29$ to -0.50 , about five times the size of the 0.06 effect we estimate. This seems likely to reflect the extent to which our calculations fail to account for the degree to which calories for FAFH reduce calories consumed at home, but suggests that the hypothesis that increased consumption of food away from home could explain the increase in body weight we find with increases in the minimum wage, even if as little as 20 percent of the increase in calories consumed away from home represents a net increase in total caloric consumption.

Our analysis has several limitations. First, BRFSS body weight and height information was self-reported, which could lead to bias in estimates of weight and height (Cawley 2004). However, there is no obvious reason why such bias would change our findings. Another limitation is that BRFSS excludes children and youth, institutionalized populations, and households without phone service. Finally, our analysis assumes that changes in minimum wages affect obesity currently, and it may well be that there is some lag structure to effects that we have failed to account for and would be complex to implement empirically given the serial correlation of wages within states over time.

\subsection{Potential Policy Implications}

If the decline in minimum wages has contributed to increasing obesity in the United States, then it is tempting to consider whether increases in the minimum wage might reduce obesity in the United States, producing benefits in both better health and lower health care costs. Indeed, the federal real minimum wage has already increased by about 40 percent since 2006 . Real minimum wages would have to rise by an additional 60 percent to restore them to their 1968 levels, and such increases could have adverse effects on employment, companies that depend on minimum wage labor, and the prices of other goods and services that are heavily dependent on minimum wage labor (Card and Krueger 2000; Neumark and Wascher 2000; Flinn 2006). 
To put the potential policy implications of a minimum wage increase in context, it is useful to consider the expected effects of minimum wage on health outcomes, such as mortality. Precisely forecasting the effects of a minimum wage change on mortality is complex because minimum wage may change obesity differently across different groups, and those changes may have varying effects on health outcomes across those groups (Flegal et al. 2005). However, using published estimates that there is an average reduction in life expectancy of about six months with each one unit increase in BMI (Fontaine et al. 2003), the change of 0.07 over the population for each dollar increase in the minimum wage would increase life expectancy in the United States by fifteen days, producing an additional twelve million lifeyears of the U.S. population. To the extent that BMI would decrease most among the most obese, as suggested by our quantile regressions, and that the health benefits of BMI reduction would be greatest at the highest levels of BMI, these estimates of the mortality reductions from an increase in the real minimum wage would be conservative.

Were an increase in the minimum wage to be viewed as a health intervention, it would be useful to consider its benefits from the perspective of cost-effectiveness. As a back-of-the-envelope calculation, using common estimates that a year of life is valued at $\$ 100,000$ (Braithwaite et al. 2008) and assuming that the added year of life would occur on average forty years from now (since the average age of the U.S. population is slightly above thirty-five and life expectancy at birth is slightly above seventy-five), ${ }^{6}$ and discounting future benefits at 3 percent (Gold et al. 1996), this increase in life expectancy would be valued at about $\$ 375$ billion. Reductions in morbidity with decreasing levels of obesity have also been quantified and are probably roughly on the same order of magnitude as reductions in mortality (Muennig et al. 2006). Health care costs related to obesity are smaller, probably less than $\$ 50$ billion annually, so the value of these savings would be small compared to the value of health improvements (Allison, Zannolli, and Narayan 1999; Raebel et al. 2004). Dividing these benefits that would accrue across all cohorts evenly among all the cohorts suggests an annual health benefit valued at about $\$ 50$ billion. The total of these societal benefits is clearly very large, but need to be interpreted in light of an estimated annual cost of a one dollar increase in minimum wage increases of about $\$ 195$ billion per year assuming that there are thirteen million minimum wage workers who each work about 1,500 hours per year. ${ }^{7}$ This suggests that an increase in the minimum wage would cost consumers on average more than they would gain in health benefits, but does not include the benefits to minimum wage workers. To the extent that these are transfer payments from consumers

6. U.S. Census Bureau (2008).

7. See, e.g., Minimum Wage Issue Guide. Economic Policy Institute, Washington, DC, July 2008. 
paying higher costs for minimum wage earners, such benefits to minimum wage earners would completely offset the costs of a minimum wage increase. However, to the extent higher minimum wages induce unemployment or other inefficiencies in labor and product markets, a result suggested by classical microeconomic theory but still controversial empirically (Neumark and Wascher 2007), such losses would have to be viewed as arguing against increases in the minimum wage. Unfortunately, estimates of the magnitude of such welfare losses due to a higher minimum wage are not available. For this reason, and because an increase in the minimum wage might have a series of complex distributional effects on different subgroups in the population, recommendations about the desirability of a further increase in the minimum wage are beyond the scope of this chapter.

Whether or not additional minimum wage increases would be a desirable policy option, our results may have important policy implications if they focus attention on the mechanisms by which an increase in the minimum wage might affect obesity. While we have emphasized food away from home, we recognize that other explanations could be produced. For example, it is possible that prices for food at home could also be influenced by changes in the minimum wage, though this seems less likely given the smaller share for minimum wage labor in the manufacture of food at home. If we are willing to focus on the price of food away from home as a determinant of obesity, then perhaps policy changes such as better labeling, public health education, regulation of serving size, or "sin taxes" on food away from home might be worth greater attention (Garson and Engelhard 2007). Although prior studies have suggested an association between obesity and increased consumption of food away from home, the direction of causation has been unclear. Our findings on the relationship of obesity to minimum wage changes support the argument that the association of increased consumption of food away from home and obesity may reflect a causal relationship. Our results also increase the importance of experiments to test approaches to control obesity by changing the consumption of food away from home, whether through changes in prices, availability, or information about health consequences.

That our findings explain only a moderate percent of the observed change in body weight suggest that other explanations, such as decreased physical activity, may also play important roles in the increase in obesity. Peer effects have also recently received significant attention in the literature (Christakis and Fowler 2007; Chen and Meltzer 2008), though these would presumably be reflected in the total response we observe in response to a change in the minimum wage, only perhaps more broadly distributed over time. Peer effects also cannot explain why a trend towards increasing obesity may have started; it is possible that decreases in the minimum wage may have had local effects that explain only ten to twenty percent of the increase in BMI as we identify here, but larger effects across the country through peer effects 
that we are unable to identify using the approach we apply here. Finally, we should note that labor saving approaches to the production of fast-food have presumably also played a major role in decreasing its cost and increasing its consumption. To the extent such labor saving continues, minimum wage labor may be an increasingly less important contributor to the cost of food away from home over time regardless of wage increases. While this may decrease the potential impact of minimum wage policies on obesity, our findings highlight the possibility that policies that focus on the consumption of food away from home deserve particular attention in public health efforts to control obesity.

\section{References}

Aaronson, D. 2001. Price pass-through and the minimum wage. Review of Economic and Statistics 83 (1): 158-69.

Aaronson, D., E. French, and J. MacDonald. 2008. The minimum wage, restaurant prices, and labor market structure. Journal of Human Resources 43 (3): 688-720.

Allison, D., R. Zannolli, and K. M. Narayan. 1999. The direct health care costs of obesity in the United States. American Journal of Public Health 89 (8): 1194-9.

Anderson, M., and D. A. Matsa. 2009. Are restaurants really supersizing America? American Economic Journal: Applied Economics, forthcoming.

Bertrand, M., E. Duflo, and S. Mullainathan. 2004. How much should we trust differences-in-differences estimates? Quarterly Journal of Economics 119 (1): 249-75.

Braithwaite, R. S., D. O. Meltzer, J. T. King, D. Leslie, and M. S. Roberts. 2008. What does the value of modern medicine say about the $\$ 50,000$ per qualityadjusted life-year decision rule? Medical Care 46 (4): 349-56.

Card, D., and A. B. Krueger. 2000. Minimum wages and employment: A case study of the fast-food industry in New Jersey and Pennsylvania: Reply. American Economic Review 90 (5): 1397-420.

Cawley, J. 2004. The impact of obesity on wages. Journal of Human Resources 39 (2): 451-74.

Centers for Disease Control and Prevention (CDC). 1984-2006. Behavioral risk factor surveillance system survey data. Atlanta, GA: U.S. Department of Health and Human Services, CDC.

Chang, V. W., and D. S. Lauderdale. 2005. Income disparities in body mass index and obesity in the United States, 1971-2002. Archives of Internal Medicine 165 (18): 2122-8.

Chen, Z., and D. O. Meltzer. 2008. Beefing up with the Chans: Evidence for the effects of relative income and income inequality on health from the China health and nutrition survey. Social Science \& Medicine 66 (11): 2206-17.

Chou, S.-Y., M. Grossman, and H. Saffer. 2004. An economic analysis of adult obesity: Results from the behavioral risk factor surveillance system. Journal of Health Economics 23:565-87.

Christakis, N. A., and J. H. Fowler. 2007. The spread of obesity in a large social network over 32 Years. New England Journal of Medicine 357:370-9. 
Cotti, C. D., and N. Tefft. 2009. Do changes in the minimum wage impact obesity in the U.S.? Available at: SSRN: http://ssrn.com/abstract $=1479307$.

Currie, J., S. DellaVigna, E. Moretti, and V. Pathania. 2009. The effect of fast food restaurants on obesity and weight gain. NBER Working Paper no. 14721. Cambridge, MA: National Bureau of Economic Research, February. Economic Policy

Cutler, D. M., E. L. Glaeser, and J. M. Shapiro. 2003. Why have Americans become more obese? Journal of Economic Perspectives 17 (3): 93-118.

Flegal, K. M., M. D. Carroll, R. J. Kuczmarski, and C. L. Johnson. 1998. Overweight and obesity in the United States: Prevalence and trends, 1960-1994. International Journal of Obesity 22:39-47.

Flegal, K. M., B. I. Graubard, D. F. Williamson, and M. H. Gail. 2005. Excess deaths associated with underweight, overweight, and obesity. Journal of the American Medical Association 293:1861-67.

Flinn, C. J. 2006. Minimum wage effects on labor market outcomes under search, matching, and endogenous contact rates. Econometrica 74 (4): 1013-62.

Fontaine, K. R., D. T. Redden, C. Wang, A. O. Westfall, and D. B. Allison. 2003. Years of life lost due to obesity. Journal of the American Medical Association 289 (2): 187-93.

Frazao, E., M. Andrews, D. Smallwood, and M. Prell. 2007. Food spending patterns of low-income households: Will increasing purchasing power result in healthier food choices? USDA Economic Research Service Economic Information Bulletin 29 (4), September.

Garson, A., and C. L. Engelhard. 2007. Attacking obesity: Lessons from smoking. Journal of the American College of Cardiology 49:1673-5.

Gibson, D. 2003. Food stamp program participation is positively related to obesity in low income women. Journal of Nutrition 133:2225-31.

- 2004. Long-term food stamp program participation is differentially related to overweight in young girls and boys. Journal of Nutrition 134:372-9.

Gold, M. R., J. E. Siegel, L. B. Russell, and M. C. Weinstein. 1996. Cost-effectiveness in health and medicine. Oxford and New York: Oxford University Press.

Kim, D., S. V. Subramanian, S. L. Gortmaker, and I. Kawachi. 2006. U.S. state- and county-level social capital in relation to obesity and physical inactivity: A multilevel, multivariable analysis. Social Science \& Medicine 63 (4): 1045-59.

Kuczmarski, R. J., K. M. Flegal, S. M. Campbell, and C. L. Johnson. 1994. Increasing prevalence of overweight among U.S. adults-The national health and nutrition surveys, 1960 to 1991. Journal of the American Medical Association 272 (3): 205-11.

Lakdawalla, D., and T. Philipson. 2002. The growth of obesity and technological change: A theoretical and empirical examination. NBER Working Paper no. 8946. Cambridge, MA: National Bureau of Economic Research, May.

Lee, C., and B. O'Roark. 1999. The impact of minimum wage increases on food and kindred products prices: An analysis of price pass-through. Food and Rural Economics Division, Economic Research Service, U.S. Department of Agriculture, Technical Bulletin No. 1877.

MacDonald, J. M., and D. Aaronson. 2006. How firms construct price changes: Evidence from restaurant responses to increased minimum wages. American Journal of Agricultural Economics 88 (2): 292-307.

Mello, M. M., D. M. Studdert, and T. A. Brenna. 2006. Obesity-The new frontier of public health law. New England Journal of Medicine 354 (24): 2601-9.

Muennig, P., E. Lubetkin, H. Jia, and P. Franks. 2006. Gender and the burden of disease attributable to obesity. American Journal of Public Health 96 (9): 1662-8. 
National Institutes of Health (NIH). 1998. Clinical guidelines on the identification, evaluation and treatment of overweight and obesity in adults: The evidence report. Obesity Research 6:51S-209S.

Nestle, M. 2006. Food marketing and childhood obesity-A matter of policy. New England Journal of Medicine 354:2527-9.

Neumark, D., and W. Wascher. 2000. Minimum wages and employment: A case study of the fast-food industry in New Jersey and Pennsylvania: Comment. American Economic Review 90 (5): 1362-96.

. 2007. Minimum wages and employment. IZA Discussion Paper no. 2570. Bonn, Germany: Institute for the Study of Labor.

Ogden, C. L., M. D. Carroll, L. R. Curtin, M. A. McDowell, C. J. Tabak, and K. M. Flegal. 2006. Prevalence of overweight and obesity in the United States, 19992004. Journal of the American Medical Association 295 (13): 1549-55.

Philipson, T. J., and R. A. Posner. 2003. The long-run growth in obesity as a function of technological change. Perspectives in Biology and Medicine 46 (3 Suppl): S87-107.

Piggott, N. E. 2003. The nested PIGLOG model: An application to U.S. food demand. American Journal of Agricultural Economics 85 (1): 1-15.

Raebel, M. A., D.C. Malone, D. A. C. Conner, S. Xu, J. A. Porter, and F. A. Lanty. 2004. Health services use and health care cost of obese and nonobese individuals. Archives of Internal Medicine 164:2135-40.

U.S. Census Bureau. 2008. Statistical abstract of the United States: Various issues. Washington, DC: GPO. Available at: http://www.census.gov/statab/www/.

U.S. Department of Labor, Employment Standards Administration. 2004. The fair labor standards act of 1938, as Amended, Wage and Hour Division. Washington, DC: WH Publication 1318, revised March 2004. 